\title{
Notch3 and its CADASIL mutants differentially regulate cellular phenotypes
}

\author{
CHUNJING LIN $^{1}$, ZIYANG HUANG ${ }^{2}$, RIYONG ZHOU ${ }^{3}$, YING ZHOU ${ }^{4}$, \\ YANGPING SHENTU ${ }^{5}$, KANG YU ${ }^{2}$ and $\mathrm{YU} \mathrm{ZHANG}^{2}$
}

\author{
Departments of ${ }^{1}$ Gastroenterology, ${ }^{2}$ Hematology, ${ }^{3}$ Anesthesiology, ${ }^{4}$ Nephrology and ${ }^{5}$ Pathology, \\ The First Affiliated Hospital of Wenzhou Medical University, Wenzhou, Zhejiang 325000, P.R. China
}

Received February 13, 2020; Accepted July 21, 2020

DOI: $10.3892 / \mathrm{etm} .2020 .9549$

\begin{abstract}
Notch3 is a member of the Notch family and its mutations are known to cause a hereditary human disorder called cerebral autosomal-dominant arteriopathy with subcortical infarcts and leukoencephalopathy (CADASIL). However, the specific function and signaling cascade initiated by CADASIL mutants remain unknown. To gain further insight into mechanism of action of CADASIL mutants, the present study conducted several experiments on the effects of Notch3 mutants in multiple cell lines. The protein levels of Notch3, fibronectin, collagen, inducible nitric oxide synthase and DNA (cytosine-5)-methyltransferase 1 (DNMT1) were determined by western blotting. The mRNA levels of IL- $1 \beta$ and TNF- $\alpha$ were measured by reverse transcription semi-quantitative PCR and DNMT1 mRNA levels were determined by quantitative PCR. Trypan blue staining was used for proliferation analysis and wound healing assays were performed to determine cell migration capability. The present study reported that R90C and R169C Notch3 mutants, and wild-type Notch3 had different effects on several cell lines. In T/GHA-VSMC cells, following the transfection of the two mutants, collagen and fibronectin expression increased, whereas expression decreased in IMR-90 cells. In BV2 cells, the two mutants resulted in decreased nitric oxide and iNOS production. In HeLa cells, proliferation and migration increased significantly following the transfection of the two mutants, whereas in the MCF-7 and HCC1937 cell lines, cell proliferation and migration decreased. In addition, the two mutants suppressed the expression of DNMT1 in HeLa and IMR-90 cells. Overall, the present study provided novel insights that further explored the underlying mechanisms of CADASIL.
\end{abstract}

Correspondence to: Ms. Yu Zhang or Professor Kang Yu, Department of Hematology, The First Affiliated Hospital of Wenzhou Medical University, Shangcai Village, South Baixiang Street, Ouhai, Wenzhou, Zhejiang 325000, P.R. China

E-mail: zhangyu486@126.com

E-mail: yukang62@126.com

Key words: Notch3, cerebral autosomal-dominant arteriopathy with subcortical infarcts and leukoencephalopathy, proliferation, migration

\section{Introduction}

Notch signaling has been demonstrated to participate in cell fate determination and in progenitor cell maintenance during development (1). In mammals, there are four Notch receptors (Notch1-4), which have distinct tissue expression patterns and are considered to function in specific cellular contexts (1). Notch3, a highly conserved type I transmembrane protein, is predominantly expressed in vascular smooth muscle cells (VSMCs) has three domains: An extracellular domain (ECD) with 34 epidermal growth factor-like repeats, a transmembrane domain and an intracellular domain (ICD), which serves an important role in VSMC maturation and differentiation (2). After binding of a ligand ( $\delta$-like protein 1 or protein jagged-1b) to the ECD, the protein undergoes three proteolytic cleavage steps, leading to the translocation of the ICD to the nucleus, where it functions as a nuclear transcription factor (3).

Highly stereotyped mutations of ECD have been associated with cerebral autosomal-dominant arteriopathy with subcortical infarcts and leukoencephalopathy (CADASIL), an inherited small vessel disease that causes stroke and dementia (4). The typical characteristic of CADASIL is progressive degeneration of VSMCs in blood vessel walls, accompanied by the accumulation of Notch3 extracellular region and the appearance of granular osmiophilic material deposits (5). In CADASIL, >170 different mutations have been detected (5). Most of these are missense point mutations complemented by a few small deletions that lead to gain or loss of a cysteine residue within an epidermal growth factor-like domain, thus altering the number of cysteine residues within a given domain from 6 to either 5 or 7 (6). This results in an unpaired cysteine that is predicted to disrupt normal disulfide bridge formation, causing misfolding of growth factor-like repeats and increased Notch3 multimerization $(7,8)$. However, the exact underlying mechanism of pathogenesis in CADASIL is yet to be elucidated. The role of CADASIL mutants in the pathogenic mechanism is controversial and several authors have reported that altered Notch3 function is not the primary determinant of the disease (9-11).

Based on the uncertain functions of the CADASIL-Notch3 mutants and the unknown mechanism of CADASIL, the present study aimed to explore the roles of mutants and wild-type (WT) Notch3 in the differential regulation of various cellular phenotypes in several cell lines. The present 
findings could serve as a molecular foundation for future studies investigating the underlying mechanism of Notch3 signaling in CADASIL and may provide an important insight for the investigation of novel CADASIL treatments.

\section{Materials and methods}

Cells. T/GHA-human aortic VSMCs (CRL-1999), human fetal lung fibroblasts (IMR-90; CCL-186), human cervical cancer cell (HeLa; CCL-2), human breast cancer (MCF-7; CRL-3435) and mouse microglia (BV2 cells;CRL-2468) were obtained from the American Type Culture Collection. Human breast cancer cells (HCC1937 cells; TCHu148) were purchased from The Cell Bank of Type Culture Collection of the Chinese Academy of Sciences. HeLa and MCF-7 cells were cultured in DMEM (Gibco; Thermo Fisher Scientific, Inc.) whereas the other cell lines were cultured in RPMI-1640 medium (Gibco; Thermo Fisher Scientific, Inc.) supplemented with 10\% FBS (Invitrogen; Thermo Fisher Scientific, Inc.), $100 \mathrm{U} / \mathrm{ml}$ penicillin and $100 \mu \mathrm{g} / \mathrm{ml}$ streptomycin (Beijing Solarbio Science \& Technology Co., Ltd.). Cells were maintained in a humidified incubator at $37^{\circ} \mathrm{C}$ with $5 \% \mathrm{CO}_{2}$. HA-VSMCs and IMR-90 cells were selected to clarify the effect of Notch 3 mutants on tunica media and adventitia, respectively. HeLa, MCF-7 and HCC1937 cells were selected to assess the role of Notch3 mutants in different types of cancer, while BV2 cells were used to evaluate the impact of Notch3 mutants on neuroinflammation.

Western blot analysis. Cells were lysed in a sample buffer containing 2\% SDS, $60 \mathrm{mM}$ Tris- $\mathrm{HCl}(\mathrm{pH} 6.8)$ and 5\% glycerol. Cell lysates were then boiled for $5 \mathrm{~min}$. Total protein concentration was determined using a BCA kit (Beyotime Institute of Biotechnology), according to the manufacturer's protocol, and equal quantities of proteins were loaded for western blot analysis. In brief, $20 \mu \mathrm{g}$ proteins were resolved by $10 \%$ SDS-PAGE, transferred to a PVDF membrane (Pall Life Sciences) and then blocked with $5 \%$ milk in TBS with $0.1 \%$ Tween- 20 for $1 \mathrm{~h}$ at room temperature. The membrane was then incubated with antibodies $(1: 1,000)$ against Notch3 (cat. no. SC-5593; Santa Cruz Biotechnology, Inc.), fibronectin (cat. no. 26836; Cell Signaling Technology, Inc.), collagen type I (cat. no. SC-59772; Santa Cruz Biotechnology, Inc.), inducible nitric oxide synthase (iNOS; cat. no. 13120; Cell Signaling Technology, Inc.), DNA (cytosine-5)-methyltransferase 1 (DNMT1; cat. no. 5032; Cell Signaling Technology, Inc.) or $\beta$-actin (cat. no. 3700; Cell Signaling Technology, Inc.) overnight at $4^{\circ} \mathrm{C}$, followed by incubation with secondary horseradish peroxidase-conjugated anti-rabbit (1:5,000; cat. no. 7074; Cell Signaling Technology, Inc.) or anti-mouse (1:5,000; cat. no. 7076; Cell Signaling Technology, Inc.) antibodies for $1 \mathrm{~h}$ at room temperature. Blots were developed using enhanced chemiluminescence reagents (LumiGLO ${ }^{\circledR}$ Reagent and Peroxide; Cell Signaling Technology, Inc.), according to the manufacturer's protocol. Densitometry was performed using ImageJ software (version 1.8.0; National Institutes of Health).

Nitric oxide $(N O)$ release assay. Nitrite level in the cell culture medium was measured as an indicator of NO production. In brief, BV2 cells were treated with LPS $(1 \mu \mathrm{g} / \mathrm{ml}$, Sigma-Aldrich; Merck KGaA) for $24 \mathrm{~h}$. Following this, $50 \mu \mathrm{l}$ supernatant was mixed with an equal volume of Griess reagent I (Beyotime Institute of Biotechnology), followed by addition of $50 \mu \mathrm{l}$ Griess reagent II (Beyotime Institute of Biotechnology) at room temperature. The absorbance was immediately measured at $540 \mathrm{~nm}$. The samples were assayed in triplicate and the concentration of each sample was calculated from a standard curve generated using sodium nitrite.

Reverse transcription semi-quantitative PCR analysis. Total RNA was extracted from BV2 cells using TRIzol ${ }^{\circledR}$ (Invitrogen; Thermo Fisher Scientific, Inc.) and reverse transcribed using the PrimeScript ${ }^{\mathrm{TM}}$ RT Master Mix (Takara Biotechnology Co., Ltd.), according to the manufacturer's protocol. Conditions for reverse transcription were $15 \mathrm{~min}$ at $37^{\circ} \mathrm{C}$ and $5 \mathrm{sec}$ at $85^{\circ} \mathrm{C}$. PCR analyses of tumor necrosis factor (TNF)- $\alpha$, interleukin (IL)- $1 \beta$ and $\beta$-actin mRNA levels were performed using 2X Taq Master Mix (Vazyme Biotech Co., Ltd.). The forward and reverse primer pairs used were as follows: TNF- $\alpha$ forward, 5'-ATCCGCGACGTGGAACTG-3' and reverse, 5'-ACCGCC TGGAGTTCTGGAA-3'; IL-1 $\beta$ forward, 5'-CTTCATCTT-3' and reverse, 5'-TCACACACCAGCAGGTTATCATC-3'; and $\beta$-actin forward, 5'-TGGCACCCAGCACAATGAA-3' and reverse, 5'-CTAAGTCATAGTCCGCCTAGAAGCA-3'. The PCR thermocycling conditions were as follows: $95^{\circ} \mathrm{C}$ for $5 \mathrm{~min}$, followed by 30 cycles of $95^{\circ} \mathrm{C}$ for $30 \mathrm{sec}, 55^{\circ} \mathrm{C}$ for $30 \mathrm{sec}$ and $72^{\circ} \mathrm{C}$ for $1 \mathrm{~min}$ and $72^{\circ} \mathrm{C}$ for $10 \mathrm{~min}$. The products were separated on a $1.2 \%$ agarose gel containing ethidium bromide and were visualized under a gel imaging system.

Quantitative PCR ( $q P C R$ ) analysis. Total RNA extraction and reverse transcription were carried out as described for semi-quantitative PCR analysis. qPCR analyses of mRNA expression levels were performed with TB Green Premix Ex Taq (Takara Biotechnology Co., Ltd.). The forward and reverse primer pairs were as follows: DNMT1 forward, 5'-GTGGGG GACTGTGTCTCTGT-3' and reverse, 5'-TGAAAGCTGCA TGTCCTCAC-3'; and $\beta$-actin forward, 5'-ATCGTGCGTGA CATTAAGGAG-3' and reverse, 5'-GAAGGAAGGCTGGAA GAGTG-3'. The qPCR thermocycling conditions were as follows: $95^{\circ} \mathrm{C}$ for $30 \mathrm{sec}$, followed by 40 cycles of $95^{\circ} \mathrm{C}$ for $3 \mathrm{sec}, 60^{\circ} \mathrm{C}$ for $30 \mathrm{sec}$. $\beta$-actin was used as the reference gene to normalize the mRNA expression of DNMT1.

Vector construction and transfection. pCMV-Sport6 Notch3 (Genbank ID: NM_000435.3) was provided by Dr Michael Wang (University of Michigan, USA). The R90C and R169C Notch3 CADASIL mutants were generated by PCR mutagenesis of the pCMV-Sport6 Notch3 vector using the following primers: R90C forward, 5'-CCC TGTGCTGGCTGTGGTGTCTGCC-3' and reverse, 5'-GGCAGACACCACAGCCAGCCAGGG-3'; and R169C forward, 5'-GTGAGCCCTGCTGCCATGGTG GCA-3' and reverse, 5'-TGCCACCATGGCAGCAGGGCTC ACC-3'. The PCR reaction was performed using Takara PrimeSTAR Max DNA Polymerase (Takara Biotechnology Co., Ltd.), according to the manufacturer's protocol. The PCR thermocycling conditions were as follows: $98^{\circ} \mathrm{C}$ for $3 \mathrm{~min}$, followed by 30 cycles of $98^{\circ} \mathrm{C}$ for $30 \mathrm{sec}, 60^{\circ} \mathrm{C}$ for $30 \mathrm{sec}, 72^{\circ} \mathrm{C}$ for $5 \mathrm{~min}$ and $72^{\circ} \mathrm{C}$ for $10 \mathrm{~min}$. The authenticity of the cloned fragments was confirmed by sequencing. A total of $2 \mu \mathrm{g}$ vectors were transfected into $5 \times 10^{5}$ cells using 
A
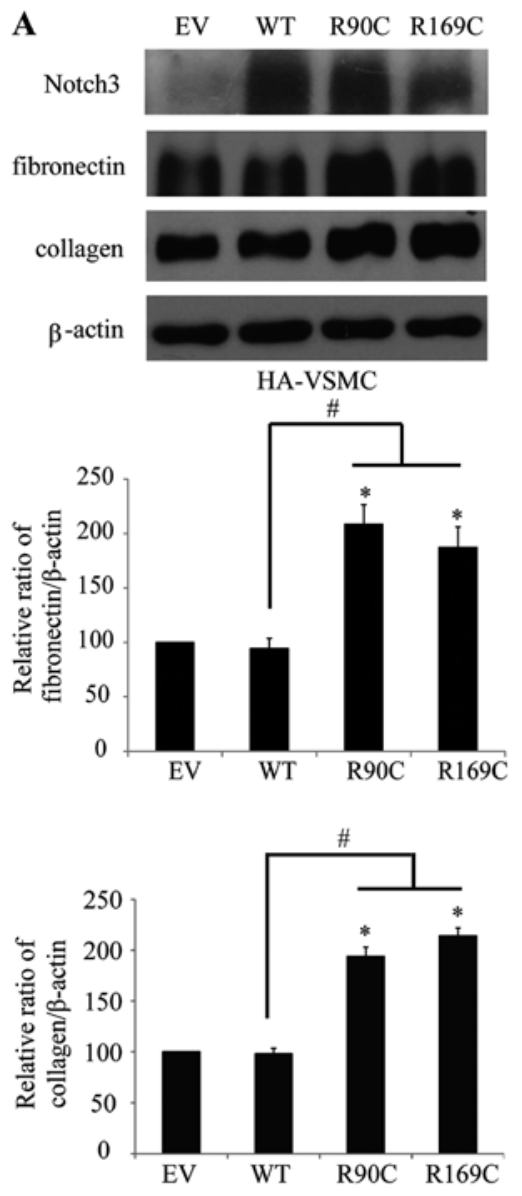
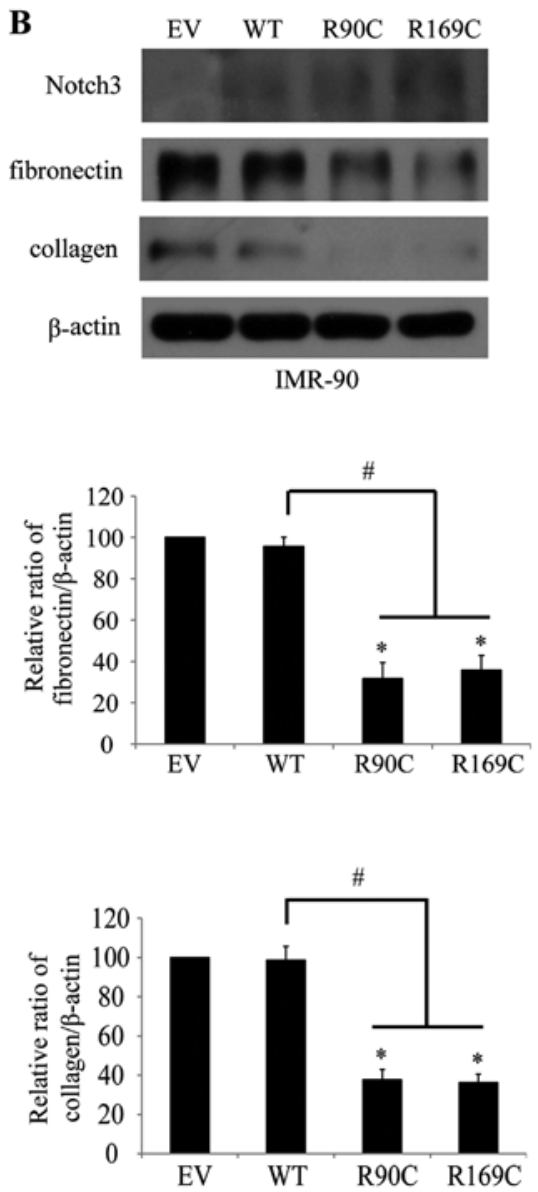

Figure 1. CADASIL mutants differentially regulate the expression of extracellular matrix proteins in VSMCs and fibroblasts. (A) R90C and R169C CADASIL-Notch3 mutants increased collagen and fibronectin levels in HA-VSMCs. (B) R90C and R169C CADASIL-Notch3 mutants decreased collagen and fibronectin levels in IMR-90 cells. Protein expression was determined 2 days after transfection of EV, WT, R90C and R169C. Protein densitometry quantification after normalization with $\beta$-actin levels is shown. Data are presented as mean \pm standard error of the mean $(\mathrm{n}=3)$. " $\mathrm{P}<0.05$ vs. EV-transfected cells. ${ }^{~} \mathrm{P}<0.05$ vs. WT-transfected cells. EV, empty vector; WT, wild-type; CADASIL, cerebral autosomal-dominant arteriopathy with subcortical infarcts and leukoencephalopathy; HA-VSMCs, human aortic vascular smooth muscle cells.

Lipofectamine ${ }^{\circledR} 2000$ (Invitrogen; Thermo Fisher Scientific, Inc.), according to the manufacturer's protocol. After $48 \mathrm{~h}$ of transfection, cells were collected for further experiments.

Proliferation assay. A total of $3 \times 10^{5}$ cells were seeded in 12-well plates and allowed to grow for $24 \mathrm{~h}$ prior to plasmid transfection. At $24 \mathrm{~h}$ post-transfection, the cells were trypsinized at $0,12,24$ and $48 \mathrm{~h}$. Following this, $10 \mu \mathrm{l}$ aliquots of cells were incubated with $10 \mu 10.4 \%$ trypan blue solution for $5 \mathrm{~min}$ at room temperature. Cells that exhibited trypan blue (viable cells) were counted using a light microscope (magnification, x100; ECLIPSE Ti; Nikon Corporation) with a hemocytometer (12).

Wound healing assay. Wound healing assays were performed as described by Song et al (13). Briefly, $3 \times 10^{5}$ cells were seeded in 12-well plates overnight and transfected with the vectors. Cells were grown to confluence for $36 \mathrm{~h}$ after transfection and wounded by scratching the monolayer with a $200-\mu 1$ pipette tip. Following this, cells were washed using pre-warmed PBS to remove cellular debris and allowed to migrate for $24 \mathrm{~h}$ in medium containing $1 \%$ FBS. Images of cell migration were captured at 0 and $24 \mathrm{~h}$ after wounding using a light microscope (magnification, x200; ECLIPSE Ti; Nikon Corporation). The relative distance between the leading edges was determined using NIS-Elements Documentation software (version no. 4.10; Nikon Corporation) and expressed as a migration index (the distance migrated in $24 \mathrm{~h}$ relative to the initial gap).

Statistical analysis. Data were analyzed using one-way ANOVA with Tukey's post hoc test using the statistical package of SPSS software (version 18; SPSS, Inc.) for Windows. Data are expressed as the mean \pm standard error of the mean from $\geq 3$ independent experiments. $\mathrm{P}<0.05$ was considered to indicate a statistically significant difference.

\section{Results}

CADASIL mutants differentially regulate the expression of extracellular matrix proteins in VSMCs and fibroblasts. A pathological study demonstrated that marked fibrotic thickening of arteriolar walls occurs in patients with CADASIL (14). Based on these data, CADASIL mutants R90C and R169C were transfected into HA-VSMCs and IMR-90 cells to elucidate the molecular mechanism of fibrosis. The results from the western blot analysis revealed that the expression level of extracellular matrix collagen and fibronectin were significantly increased after the transfection of mutants (however, this did not occur in WT) in HA-VSMCs (Fig. 1A), which is consistent with 
$\mathbf{A}$

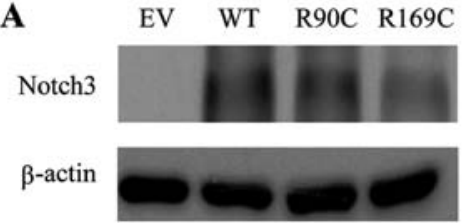

B

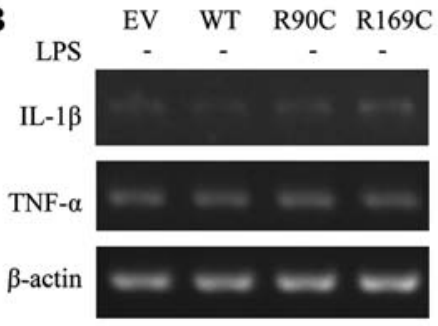

C

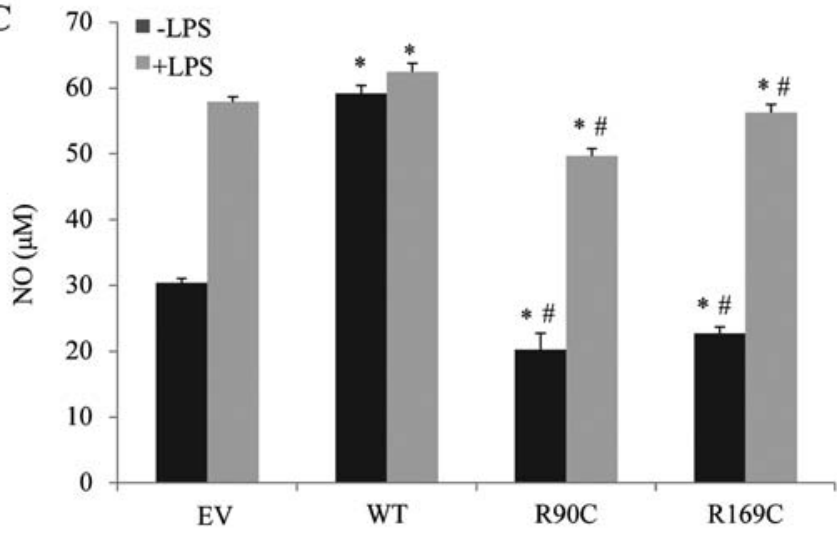

D

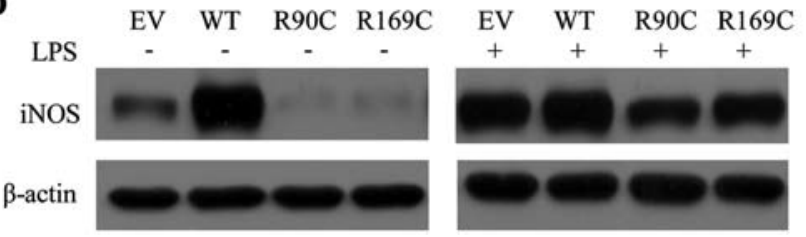

Figure 2. CADASIL mutants downregulate the level of NO and iNOS in BV2 cells. (A) EV, WT, R90C and R169C were transfected into BV2 cells and Notch3 protein expression was detected by western blotting. (B) R90C and R169C CADASIL-Notch3 mutants had no effect on the mRNA expression of TNF- $\alpha$ or IL-1 $\beta$. R90C and R169C CADASIL-Notch3 mutants decreased (C) NO and (D) iNOS levels. The NO level was determined by the Griess method, while the iNOS level was detected by western blotting 2 days after transfection. Protein densitometry quantification after normalization with $\beta$-actin levels is shown. Data are presented as mean \pm standard error of the mean $(\mathrm{n}=3)$. ${ }^{*} \mathrm{P}<0.05$ vs. EV-transfected cells. ${ }^{\text {"P }}<0.05$ vs. WT-transfected cells. EV, empty vector; WT, wild-type; NO, nitric oxide; iNOS, inducible nitric oxide synthase; CADASIL, cerebral autosomal-dominant arteriopathy with subcortical infarcts and leukoencephalopathy; TNF- $\alpha$, tumor necrosis factor- $\alpha$; IL- $1 \beta$, interleukin- $1 \beta$.

CADASIL pathology (15). By contrast, the results showed a different trend in IMR-90 cells, where collagen and fibronectin were significantly decreased after transfection of mutants; however, this did not occur in WT (Fig. 1B). These results indicated that there was differential regulation of the extracellular matrix between CADASIL mutants and Notch3 WT in VSMCs and fibroblasts.

CADASIL mutants downregulate the levels of NO and iNOS in microglia. It has been reported that the activated Notch signaling pathway regulate the proliferation and differentiation of neural precursor cells, mediate the release of inflammatory mediators and promote angiogenesis (16). Additionally, it serves an important role in nerve damage repair, inflammatory response and angiogenesis in ischemic areas (17). Abnormal regulation of glial cells was observed in patients with CADASIL (18). Thus, it was hypothesized that inflammation may be involved in the pathogenesis of CADASIL. According to the aforementioned findings, R90C and R169C Noctch3 mutants, as well as Notch 3 WT, were transfected into BV2 cells to study their roles in the regulation of the inflammatory response following LPS administration. The transfection efficiency of R90C, R169C and WT Notch3 vectors was confirmed by western blotting (Fig. 2A). mRNA analysis showed that the expression levels of TNF- $\alpha$ and IL-1 $\beta$ were not altered by transfection with the mutants compared with those transfected with WT Notch3 with or without LPS treatment (Fig. 2B). Next, the level of NO in the culture medium was detected. The results showed that the NO level of the cells transfected with mutants was significantly lower compared with the cells transfected with WT with or without LPS treatment (Fig. 2C). Furthermore, the protein level of iNOS was in accordance with the change in NO (Fig. 2D). This indicated that downregulation of $\mathrm{NO}$, which is a vasodilator factor, may be involved in the pathogenesis of CADASIL.

CADASIL mutants promote the proliferation and migration of HeLa cells; however, they inhibit those of breast cancer cells. It has been reported that Notch3 protein, which is present in numerous types of tumors, serves an important role in promoting tumor progression (19). In the present study, HeLa cells were used to assess the effects of the mutants on cell proliferation and migration, in which no apparent difference was observed among Notch3-transfected and EV-transfected cells. All Notch3 vectors effectively enhanced Notch3 expression in HeLa cells (Fig. 3A). Exogenous expression of WT Notch3 led to a significant increase in cell proliferation (Fig. 3B) and migration (Fig. 3C); however, R90C and R169C exhibited a stronger promoter effect on HeLa cells compared with WT. The aforementioned results showed that both WT and CADASIL mutants were involved in the regulation of the phenotype in HeLa cells; however, the regulatory effects of CADASIL mutants were more apparent compared with WT. Additional cancer cells were employed to explore whether the malignancy-promoting effect of Notch3 is cell-specific or general. Notch3 proteins were remarkably increased in MCF-7 cells by Notch3 mutants and WT vectors transfection (Fig. 4A). Notably, opposite outcomes to those observed in HeLa cells were observed in MCF-7 cells transfected with mutants, since the expression of exogenous Notch3 mutants significantly inhibited the proliferation of MCF-7 cells at $48 \mathrm{~h}$ compared with the results upon transfection with $\mathrm{EV}$ at 12, 24 and $48 \mathrm{~h}$, and those transfected with WT (Fig. 4B). The results of the wound healing assay showed that overexpression of Notch3 mutants significantly inhibited the migration of MCF-7 cells compared with cells transfected with WT (Fig. 4C). There was no significant difference between transfected mutants and EV on the migration of MCF-7 cells. In view of the aforementioned results, it was concluded that this differential regulation may be associated with the type of cancer cells. To further verify this conclusion, HCC1937 cells, which are also breast cancer 

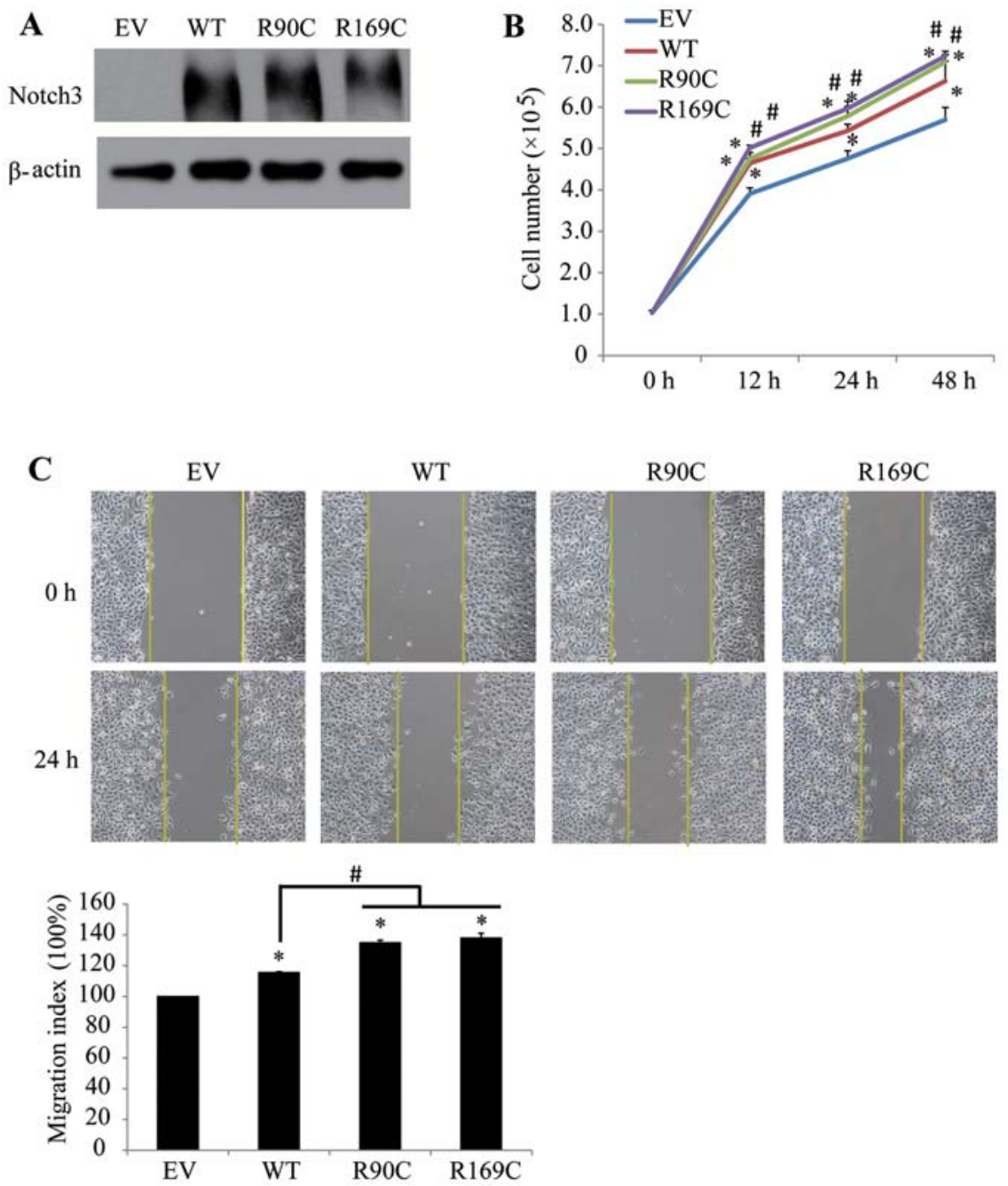

Figure 3. Cerebral autosomal-dominant arteriopathy with subcortical infarcts and leukoencephalopathy mutants promote HeLa cell malignancy. (A) EV, WT, R90C and R169C were transfected into HeLa cells and Notch3 protein expression was detected by western blotting. (B) The numbers of EV-, WT-, R90C- and $\mathrm{R} 169 \mathrm{C}$-transfected cells were counted at $0-48 \mathrm{~h}$ post-transfection. (C) The results of the wound healing assay are expressed as the migration index (the distance migrated relative to the initial scraped gap) and that of EV-transfected cells was set as $100 \%$. Data are presented as mean \pm standard error of the mean $(\mathrm{n}=3)$. ${ }^{*} \mathrm{P}<0.05$ vs. EV-transfected cells. ${ }^{*} \mathrm{P}<0.05$ vs. WT-transfected cells. EV, empty vector; WT, wild-type.

cells, were selected for further investigation. HCC1937 cells and MCF-7 cells exhibited similar changes in proliferation and migration following transfection of CADASIL mutants (Fig. 5A-C). These results suggested that the differential regulation of phenotype between CADASIL mutants R90C and R169C and WT was associated with cell type.

CADASIL mutants downregulate DNMT1 in HeLa and IMR-90 cells. DNMT1 serves a critical role in the maintenance of the genetic stability of methylation sites during replication (20). Abnormal expression of DNMT1 can lead to unusual DNA methylation and further affect gene expression and disease progression (20). The present study assessed the regulation of CADASIL mutants and Notch3 WT on DNMT1 as a preliminary exploration of the underlying mechanism. The results showed that CADASIL mutants significantly downregulated the protein expression of DNMT1 in HeLa (Fig. 6A) and IMR-90 (Fig. 6B) cells, whereas WT had no effect. To further explore the mechanism underlying CADASIL mutants-mediated reduction of DNMT1, mRNA expression of DNMT1 was analyzed. The data implied that
CADASIL mutants reduced the mRNA expression of DNMT1 in HeLa (Fig. 6C) and IMR-90 (Fig. 6D) cells, indicating that the regulatory events may occur at the transcriptional level. This suggested that there may be deregulation of DNA methylation in CADASIL, which may provide a novel insight for the exploration of subsequent pathogenesis.

\section{Discussion}

Mutations in genes encoding Notch proteins lead to a range of dysfunctions and diseases (21). Notch1 mutations have been reported in a wide variety of human diseases, including Adams-Oliver syndrome (22), left-sided congenital heart disease (23) and bicuspid aortic valve disease (24). Notch2 mutations are involved in the development of Alagille syndrome (25), while mutations in Notch3 can cause CADASIL. Diseases associated with Notch4 mutations have not been thoroughly studied (21). The most common mutations of Notch3 in CADASIL are R133C, R141C, R182C, R153C, R169C and R90C (26). In the present study, R90C and R169C CADASIL-Notch3 mutants and Notch3 WT had different 
A

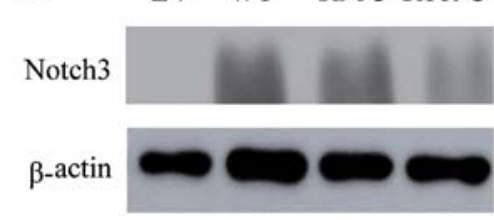

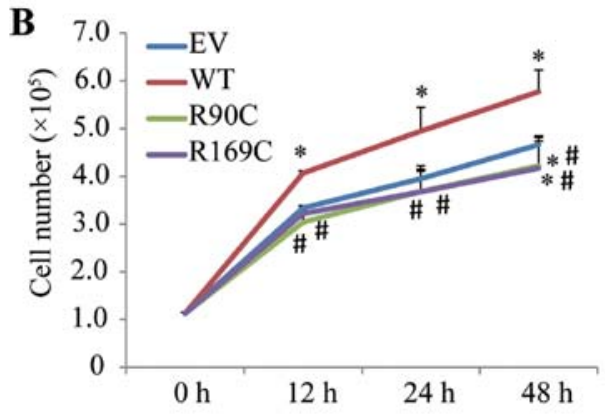

C EV WT
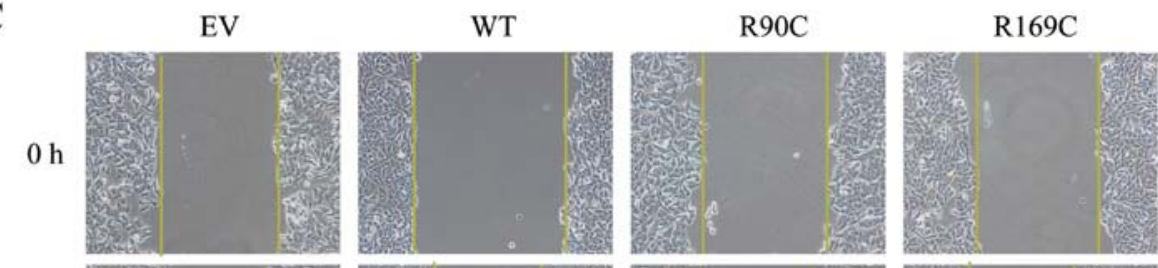

$24 \mathrm{~h}$
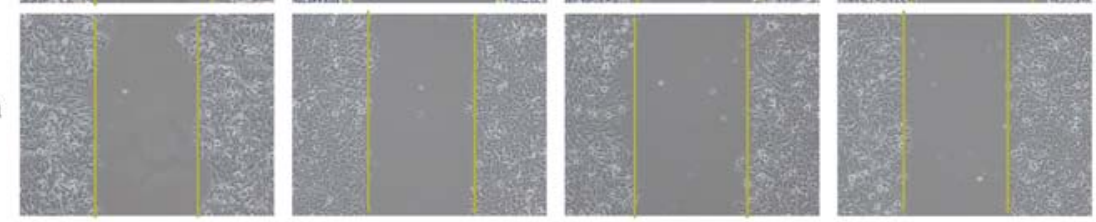

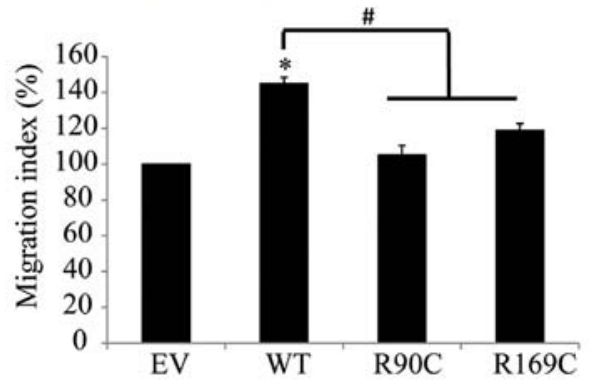

Figure 4. Inhibitory effect of cerebral autosomal-dominant arteriopathy with subcortical infarcts and leukoencephalopathy mutants on MCF-7 cell malignancy. (A) EV, WT, R90C and R169C were transfected into MCF-7 cells and Notch3 protein expression was detected by western blotting. (B) The numbers of EV-, WT-, R90C- and R169C-transfected cells were counted at 0-48 h post-transfection. (C) The results of the wound healing assay are expressed as the migration index (the distance migrated relative to the initial scraped gap) and that of EV-transfected cells was set as $100 \%$. Data are presented as mean \pm standard error of the mean $(n=3) .{ }^{*} \mathrm{P}<0.05$ vs. EV-transfected cells; ${ }^{\text {P }}<0.05$ vs. WT-transfected cells. EV, empty vector; WT, wild-type.

impacts on several cell lines, suggesting that Notch3 mutants may have more biological functions beyond current knowledge.

Stenosis of cerebral white matter arterioles with fibrosis and thickening of their walls have been attributed to accumulation of various extracellular matrix components, which can lead to decreased cerebral blood flow to such a severity that lacunar infarcts occur in CADASIL (18). It had been reported that, in diseased arteries, types I, III and VI collagen spread from an external location (adventitia) into the vascular media, while type IV collagen accumulated in an internal pattern (intima and media) (27), which is consistent with the present results. No major leakage of plasma fibrinogen or fibronectin was observed in a previous study (15). In the present study, fibronectin was observed to increase in HA-VSMCs following transfection with mutants, whereas in IMR-90 cells, collagen and fibronectin were decreased following transfection. Oide et al (28) reported that extensive arterial medial smooth muscle cells and arterial adventitia extracellular matrix were lost in CADASIL, which led to diffuse leukoencephalopathy. It is commonly known that the adventitia is primarily composed of fibroblasts. According to the aforementioned results, it was suggested that Notch3 mutants affected the physiological characteristics of arteries by two mechanisms: i) Upregulation of extracellular matrix in VSMCs, which may induce fibrotic thickening of arteriolar; and ii) downregulation of extracellular matrix in fibroblasts, which may deprive the structural and functional ability of the cerebrovascular system to regulate the cerebral blood flow, most likely due to the loss of arterial medial smooth muscle cells and mural extracellular matrix.

Neuroinflammation mediated by microglia serves an important role in damage of the central nervous system and prognosis of the disease (18). In a previous study, activation of the Notch signaling pathway caused nerve damage, which contributed to the infiltration of inflammatory cells via microglia activation (17). Abnormal regulation of glial cells was observed in patients with CADASIL (29). Thus, a microglial cell model of CADASIL was established to study the regulation of CADASIL mutants on the inflammatory response. Both NO and iNOS levels observed in two mutants groups were much lower compared with the WT group with or without LPS treatment. Considering that NO is a factor that contributes to vasodilatation and patients with CADASIL often 

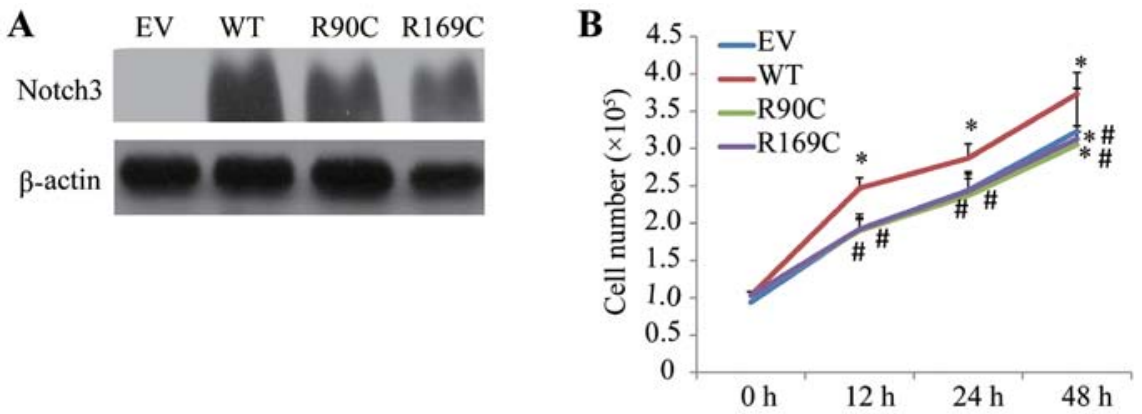

C
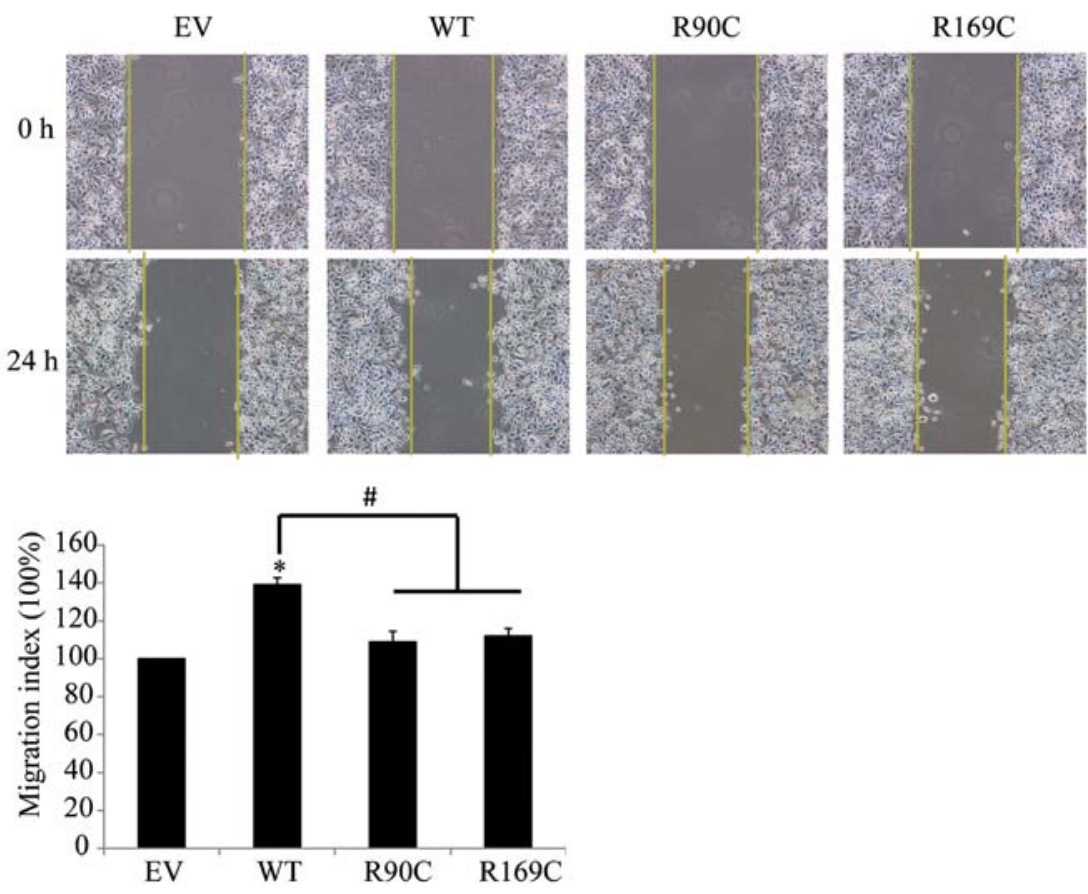

Figure 5. Inhibitory effect of cerebral autosomal-dominant arteriopathy with subcortical infarcts and leukoencephalopathy mutants on HCC1937 cell malignancy. (A) EV, WT, R90C and R169C were transfected into HCC1937 cells and Notch3 protein expression was detected by western blotting. (B) The numbers of EV-, WT-, R90C- and R169C-transfected cells were counted at $0-48 \mathrm{~h}$ post-transfection. (C) The results of the wound healing assay are expressed as the migration index (the distance migrated relative to the initial scraped gap) and that of EV-transfected cells was set as $100 \%$. Data are presented as mean \pm standard error of the mean $(\mathrm{n}=3)$. "P<0.05 vs. EV-transfected cells. ${ }^{*} \mathrm{P}<0.05$ vs. WT-transfected cells. EV, empty vector; WT, wild-type.

suffer ischemic stroke or subcutaneous infarction, limited $\mathrm{NO}$ availability may contribute to an increase in the resting vasomotor tone and, therefore, may serve an important role in cerebral ischemia (30). It has been reported that cerebral vasoreactivity enhanced by L-arginine, which is the substrate for NOS, may have therapeutic implications for CADASIL (31). In terms of a pathogenic role of impaired cerebral hemodynamics and endothelial dysfunction in CADASIL, it was hypothesized that Notch 3 mutants may also affect the synthesis of NO in endothelial cells. However, further studies are required to explore this.

Notch3 primarily serves a role in promoting cancer development and it has been detected in multiple types of tumor, including ovarian, cervical, breast and colon cancer (19). Compared with the effects of Notch3 WT, CADASIL mutants promoted the proliferation and migration of HeLa cells and inhibit these of breast cancer cells. A previous study observed hyperplasia in organs, including the liver, kidney and prostate in patients with CADASIL (32). The autopsy examination of a Japanese case revealed that, besides the vascular and neurological lesions characteristic of CADASIL, multiple neoplastic lesions were also observed, including carcinoid tumorlets and diffuse idiopathic pulmonary neuroendocrine cell hyperplasia in the lungs, renal cell carcinoma, prostatic adenocarcinoma and adenomatoid tumor of the epididymis (33). Combined with the present data, this suggested that Notch3 mutants may contribute to the increased or decreased risks of different cancer types in CADASIL.

Cerebral small vessel disease (CSVD) is one of the most common nervous system disease worldwide (1920-2017) and is considered an important pathological process of subcortical structures such as lacunar infarcts, white matter lesions and microbleeds (34). CSVD is an important cerebral microvascular pathogenesis, since it is the cause of $20 \%$ of strokes worldwide (1920-2017) and the most common cause of cognitive impairment and dementia, including vascular dementia (34). It has been reported that CSVD contributes to the occurrence of Alzheimer's disease (AD) and CADASIL (35). The association between epigenetics and CSVD has not yet been established; however, research on cerebrovascular 
A

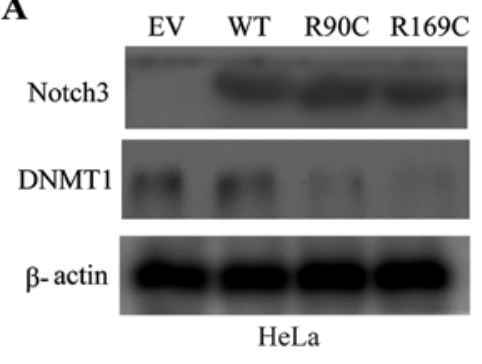

B

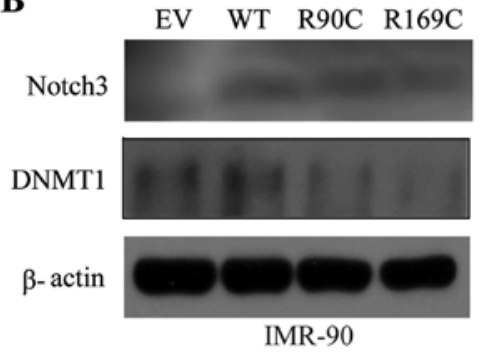

C

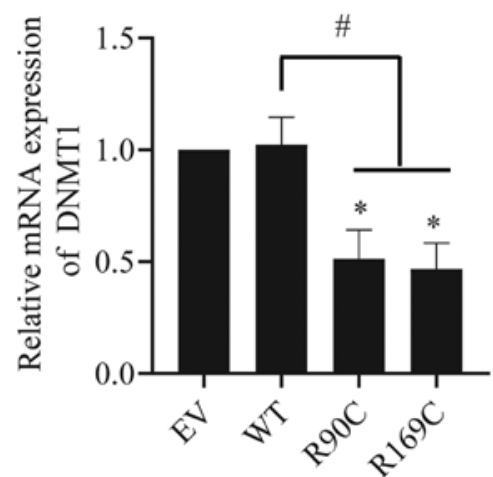

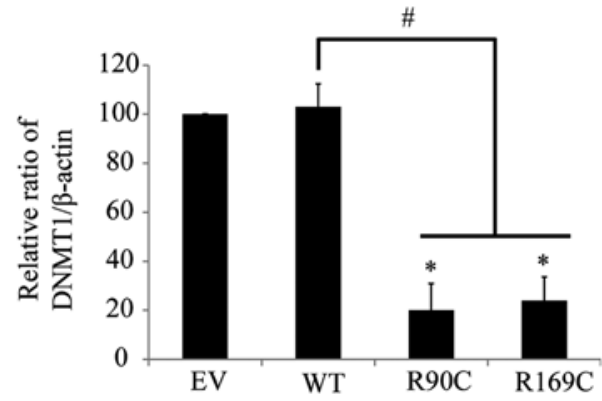

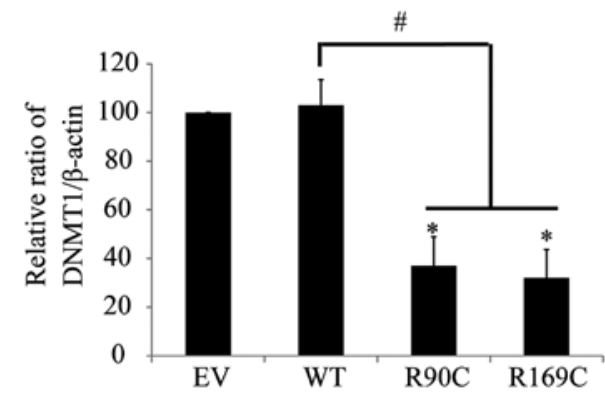

D

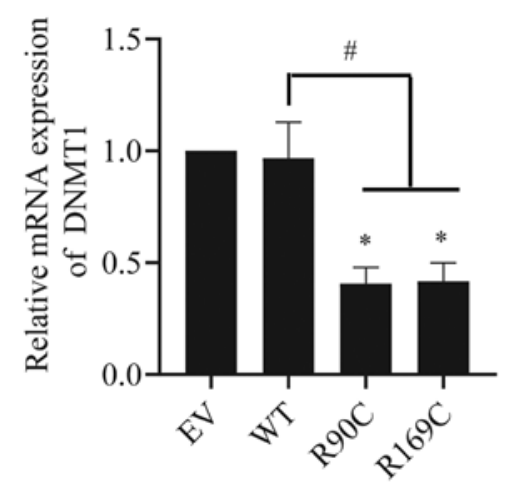

Figure 6. CADASIL mutants downregulate the expression of DNMT1 in HeLa and IMR-90 cells. R90C and R169C CADASIL-Notch3 mutants decreased the protein expression of DNMT1 in (A) HeLa and (B) IMR-90 cells. Protein expression was determined 2 days after transfection of EV, WT, R90C and R169C. Protein densitometry semi-quantification after normalization with $\beta$-actin levels are shown. R90C and R169C CADASIL-Notch3 mutants decreased the mRNA expression of DNMT1 in (C) HeLa and (D) IMR-90 cells. Data are presented as mean \pm standard error of the mean ( $\mathrm{n}=3$ ). ${ }^{*} \mathrm{P}<0.05$ vs. EV-transfected cells. ${ }^{\#} \mathrm{P}<0.05$ vs. WT-transfected cells. CADASIL, cerebral autosomal-dominant arteriopathy with subcortical infarcts and leukoencephalopathy; EV, empty vector; WT, wild-type; DNMT1, DNA (cytosine-5-)-methyltransferase 1.

diseases and DNA methylation are gradually increasing, particularly on DNA methylation abnormalities in stroke (36). A previous study that discovered the mechanism of cerebral small vessel injury aided the present study (36). Furthermore, another previous study reported that DNA methylation served an important role in gene transcription, gene imprinting and embryo development (20). DNMT1 primarily maintained the genetic stability of the methylation site during the replication process and its abnormal expression lead to dysregulation of DNA methylation, therefore affecting gene expression and disease progression (20). To the best of our knowledge, the present study is the first to report that CADASIL mutants significantly inhibited DNMT1 mRNA and protein expression in both HeLa and IMR-90 cells, whereas WT Notch3 had no effect.

Multiple studies have revealed that abnormal DNA methylation was associated with AD $(37,38)$. Both the mRNA and protein levels of DNMT1 and DNMT3a, as well as those of methyl $\mathrm{CpG}$ binding protein 2, have been demonstrated to be downregulated in AD (39). However, the exact underlying mechanism remains to be discovered. It was reported that a pathogenic presenilin mutation in $\mathrm{AD}$ caused a specific increase in p53 protein (40), which was found to block the transcription of the DNMT1 gene by binding to its promoter region in hepatocellular carcinoma, ovarian cancer and pancreatic ductal adenocarcinoma (41). Whether the downregulation of DNMT1 in CADASIL and AD was also regulated by p3-mediated transcriptional inhibition needs to be further explored. The present data suggested that there may be an abnormal regulation of DNA methylation in CADASIL, which provides a novel approach for the exploration of subsequent pathogenesis.

In summary, the present study revealed that Notch3 mutants had differential effects depending on cell type, suggesting that Notch3 mutants may have more biological functions beyond our current knowledge. These results provided novel avenues for further research on the pathogenesis of CADASIL and future studies need to be carried out to elucidate the specific pathways or underlying mechanisms of this differential regulation. 


\section{Acknowledgements}

Not applicable.

\section{Funding}

The present study was funded by the Natural Science Foundation of Zhejiang Province, China (grant no. LQ19H080003).

\section{Availability of data and materials}

All data generated or analyzed during this study are included in this published article.

\section{Authors' contributions}

YuZ, KY and CL conceived and designed the current study. $\mathrm{ZH}$ and RZ conducted the research. YiZ and YS analyzed data and wrote the manuscript. KY and CL revised the manuscript. All authors read and approved the final manuscript.

\section{Ethics approval and consent to participate}

Not applicable.

\section{Patient consent for publication}

Not applicable.

\section{Competing interests}

The authors declare that they have no competing interests.

\section{References}

1. Bray SJ: Notch signalling in context. Nat Rev Mol Cell Biol 17: 722-735, 2016.

2. Domenga V, Fardoux P, Lacombe P, Monet M, Maciazek J, Krebs LT, Klonjkowski B, Berrou E, Mericskay M, Li Z, et al: Notch3 is required for arterial identity and maturation of vascular smooth muscle cells. Genes Dev 18: 2730-2735, 2004.

3. Wang T, Baron M and Trump D: An overview of Notch3 function in vascular smooth muscle cells. Prog Biophys Mol Biol 96: 499-509, 2008

4. Joutel A, Corpechot C, Ducros A, Vahedi K, Chabriat H, Mouton P, Alamowitch S, Domenga V, Cécillion M, Marechal E, et al: Notch3 mutations in CADASIL, a hereditary adult-onset condition causing stroke and dementia. Nature 383: 707-710, 1996.

5. Hervé D and Chabriat H: Cadasil. J Geriatr Psychiatry Neurol 23: 269-276, 2010

6. Joutel A, Vahedi K, CorpechotC,Troesch A,ChabriatH, VayssièreC, Cruaud C, Maciazek J, Weissenbach J, Bousser MG, et al: Strong clustering and stereotyped nature of Notch 3 mutations in CADASIL patients. Lancet 350: 1511-1515, 1997.

7. Dichgans M, Ludwig H, Müller-Höcker J, Messerschmidt A and Gasser T: Small in-frame deletions and missense mutations in CADASIL: 3D models predict misfolding of Notch3 EGF-like repeat domains. Eur J Hum Genet 8: 280-285, 2000.

8. Duering M, Karpinska A, Rosner S, Hopfner F, Zechmeister M, Peters N, Kremmer E, Haffner C, Giese A, Dichgans M, et al: Co-aggregate formation of CADASIL-mutant NOTCH3: A single-particle analysis. Hum Mol Genet 20: 3256-3265, 2011.

9. Cognat E, Baron-Menguy C, Domenga-Denier V, Cleophax S, Fouillade C, Monet-Leprêtre M, Dewerchin M and Joutel A: Archetypal Arg169Cys mutation in NOTCH3 does not drive the pathogenesis in cerebral autosomal dominant arteriopathy with subcortical infarcts and leucoencephalopathy via a loss-of-function mechanism. Stroke 45: 842-849, 2014.
10. Joutel A: Pathogenesis of CADASIL: Transgenic and knock-out mice to probe function and dysfunction of the mutated gene, Notch3, in the cerebrovasculature. BioEssays 33: 73-80, 2011.

11. Rutten JW, Haan J, Terwindt GM, van Duinen SG, Boon EM and Lesnik Oberstein SA: Interpretation of NOTCH3 mutations in the diagnosis of CADASIL. Expert Rev Mol Diagn 14: 593-603, 2014.

12. Yamaguchi N, Oyama T, Ito E, Satoh H, Azuma S, Hayashi M, Shimizu K, Honma R, Yanagisawa Y, Nishikawa A, et al: NOTCH3 signaling pathway plays crucial roles in the proliferation of ErbB2-negative human breast cancer cells. Cancer Res 68: 1881-1888, 2008.

13. Song G, Zhang Y and Wang L: MicroRNA-206 targets notch3, activates apoptosis, and inhibits tumor cell migration and focus formation. J Biol Chem 284: 31921-31927, 2009.

14. Miao Q, Paloneva T, Tuisku S, Roine S, Poyhonen M, Viitanen M and Kalimo H: Arterioles of the lenticular nucleus in CADASIL. Stroke 37: 2242-2247, 2006.

15. Dong H, Blaivas M and Wang MM: Bidirectional encroachment of collagen into the tunica media in cerebral autosomal dominant arteriopathy with subcortical infarcts and leukoencephalopathy. Brain Res 1456: 64-71, 2012.

16. Grandbarbe L, Michelucci A, Heurtaux T, Hemmer K, Morga E and Heuschling P: Notch signaling modulates the activation of microglial cells. Glia 55: 1519-1530, 2007.

17. Yao L, Cao Q, Wu C, Kaur C, Hao A and Ling EA: Notch signaling in the central nervous system with special reference to its expression in microglia. CNS Neurol Disord Drug Targets 12: 807-814, 2013.

18. Dichgans M: Cognition in CADASIL. Stroke 40 (Suppl): S45-S47, 2009.

19. Aburjania Z, Jang S, Whitt J, Jaskula-Stzul R, Chen H and Rose JB: The Role of Notch3 in Cancer. Oncologist 23: 900-911, 2018.

20. Edwards JR, Yarychkivska O, Boulard M and Bestor TH: DNA methylation and DNA methyltransferases. Epigenetics Chromatin 10: 23, 2017.

21. Meester JAN, Verstraeten A, Alaerts M, Schepers D, Van Laer L and Loeys BL: Overlapping but distinct roles for $\mathrm{NOTCH}$ receptors in human cardiovascular disease. Clin Genet 95: 85-94, 2019.

22. Southgate L, Sukalo M, Karountzos ASV, Taylor EJ, Collinson CS, Ruddy D, Snape KM, Dallapiccola B, Tolmie JL, Joss S, et al: Haploinsufficiency of the NOTCH1 Receptor as a Cause of Adams-Oliver Syndrome With Variable Cardiac Anomalies. Circ Cardiovasc Genet 8: 572-581, 2015.

23. Kerstjens-Frederikse WS, van de Laar IM, Vos YJ, Verhagen JM, Berger RM, Lichtenbelt KD, Klein Wassink-Ruiter JS, van der Zwaag PA, du Marchie Sarvaas GJ, Bergman KA, et al: Cardiovascular malformations caused by NOTCH1 mutations do not keep left: Data on 428 probands with left-sided CHD and their families. Genet Med 18: 914-923, 2016.

24. Mohamed SA, Aherrahrou Z, Liptau H,Erasmi AW, Hagemann C, Wrobel S, Borzym K, Schunkert H, Sievers HH and Erdmann J: Novel missense mutations (p.T596M and p.P1797H) in NOTCH1 in patients with bicuspid aortic valve. Biochem Biophys Res Commun 345: 1460-1465, 2006.

25. McDaniell R, Warthen DM, Sanchez-Lara PA, Pai A, Krantz ID, Piccoli DA and Spinner NB: NOTCH2 mutations cause Alagille syndrome, a heterogeneous disorder of the notch signaling pathway. Am J Hum Genet 79: 169-173, 2006.

26. Haritunians T, Chow T, De Lange RP, Nichols JT, Ghavimi D, Dorrani N, St Clair DM, Weinmaster G and Schanen C: Functional analysis of a recurrent missense mutation in Notch3 in CADASIL. J Neurol Neurosurg Psychiatry 76: 1242-1248, 2005.

27. Miao Q, Paloneva T, Tuominen S, Pöyhönen M, Tuisku S, Viitanen $\mathrm{M}$ and Kalimo $\mathrm{H}$ : Fibrosis and stenosis of the long penetrating cerebral arteries: The cause of the white matter pathology in cerebral autosomal dominant arteriopathy with subcortical infarcts and leukoencephalopathy. Brain Pathol 14: 358-364, 2004.

28. Oide T, Nakayama H, Yanagawa S, Ito N, Ikeda S and Arima K: Extensive loss of arterial medial smooth muscle cells and mural extracellular matrix in cerebral autosomal recessive arteriopathy with subcortical infarcts and leukoencephalopathy (CARASIL). Neuropathology 28: 132-142, 2008.

29. MiaoQ,KalimoH,Bogdanovic N,Kostulas K,Börjesson-Hanson A and Viitanen M: Cerebral arteriolar pathology in a 32-year-old patient with CADASIL. Neuropathol Appl Neurobiol 32: 455-458, 2006. 
30. DeMartino AW, Kim-Shapiro DB, Patel RP and Gladwin MT: Nitrite and nitrate chemical biology and signalling. Br J Pharmacol 176: 228-245, 2019.

31. Peters N, Freilinger T, Opherk C, Pfefferkorn T and Dichgans M: Enhanced L-arginine-induced vasoreactivity suggests endothelial dysfunction in CADASIL. J Neurol 255: 1203-1208, 2008.

32. Ling Y, De Guio F, Jouvent E, Duering M, Hervé D, Guichard JP, Godin O, Dichgans $\mathrm{M}$ and Chabriat $\mathrm{H}$ : Clinical correlates of longitudinal MRI changes in CADASIL. J Cereb Blood Flow Metab 39: 1299-1305, 2019.

33. Hassan WA, Udaka N, Ueda A, Ando Y and Ito T: Neoplastic lesions in CADASIL syndrome: Report of an autopsied Japanese case. Int J Clin Exp Pathol 8: 7533-7539, 2015.

34. Søndergaard CB, Nielsen JE, Hansen CK and Christensen H: Hereditary cerebral small vessel disease and stroke. Clin Neurol Neurosurg 155: 45-57, 2017.

35. Müller K, Courtois G, Ursini MV and Schwaninger M: New Insight Into the Pathogenesis of Cerebral Small-Vessel Diseases. Stroke 48: 520-527, 2017.

36. Baccarelli A, Wright R, Bollati V, Litonjua A, Zanobetti A, Tarantini L, Sparrow D, Vokonas P and Schwartz J: Ischemic heart disease and stroke in relation to blood DNA methylation. Epidemiology 21: 819-828, 2010

37. Altuna M, Urdánoz-Casado A, Sánchez-Ruiz de Gordoa J, Zelaya MV,Labarga A, Lepesant JMJ, Roldán M, Blanco-Luquin I, Perdones A, Larumbe R, et al: DNA methylation signature of human hippocampus in Alzheimer's disease is linked to neurogenesis. Clin Epigenetics 11: 91, 2019.
38. Yokoyama AS, Rutledge JC and Medici V: DNA methylation alterations in Alzheimer's disease. Environ Epigenet 3: dvx008, 2017.

39. Bihaqi SW and Zawia NH: Alzheimer's disease biomarkers and epigenetic intermediates following exposure to $\mathrm{Pb}$ in vitro. Curr Alzheimer Res 9: 555-562, 2012.

40. Bialopiotrowicz E, Szybinska A, Kuzniewska B, Buizza L, Uberti D, Kuznicki J and Wojda U: Highly pathogenic Alzheimer's disease presenilin 1 P117R mutation causes a specific increase in p53 and p21 protein levels and cell cycle dysregulation in human lymphocytes. J Alzheimers Dis 32: 397-415, 2012.

41. Enane FO, Saunthararajah Y and Korc M: Differentiation therapy and the mechanisms that terminate cancer cell proliferation without harming normal cells. Cell Death Dis 9: 912-926, 2018

c) (i) $\ominus$ This work is licensed under a Creative Commons EY NG No Attribution-NonCommercial-NoDerivatives 4.0 International (CC BY-NC-ND 4.0) License. 